\title{
The effect of intrathecal sufentanil preconditioning against myocardial ischemia-reperfusion injury
}

\author{
Tire $\mathrm{Y}^{1}$, Sarkilar $\mathrm{G}^{2}$, Esen $\mathrm{H}^{3}$, Onoglu $\mathrm{R}^{4}$, Uzun $\mathrm{ST}^{5}$ \\ Konya Public Hospitals Association, Health Sciences University, Konya Meram Education \\ and Research Hospital, Konya, Turkey. dryasintire@hotmail.com
}

\begin{abstract}
OBJECTIVES: We aimed to investigate the cardioprotective effect and hemodynamic response of intrathecally administered sufentanil on myocardial IR injury.

BACKGROUND: Sufentanil, mu opioid receptor agonist, intravenously administered during clinical and experimental studies, has been shown to have a cardioprotective effect on myocardial ischemia-reperfusion injury. METHODS: Thirty-two New Zealand type rabbits, which were anesthetized, were divided into four equal groups: sham, ischemia-reperfusion, sufentanil and ischemia-reperfusion+sufentanil. Sufentanil was administered intrathecally prior to ischemia. Hemodynamic parameters were monitored by electrocardiography and invasive arterial blood pressure measurements. In the ischemia-reperfusion groups, the degree of myocardial infarct was determined as the ratio of ischemic region to the risk area by a $1 \% 2,3,5$-triphenyl tetrazolium chloride staining. RESULTS: The mean infarct size in the ischemia-reperfusion group was $47.5 \pm 7.0 \%$, whereas that of the ischemia-reperfusion+sufentanil group was found to be $34.2 \pm 4.7 \%$, indicating a statistically significant difference $(p=0.002)$. The heart rate was different between the ischemia-reperfusion and the sufentanil groups for baseline measurement and between the ischemia-reperfusion and the ischemia-reperfusion+sufentanil groups at the 120th minutes measurement $(p<0.05)$.

CONCLUSION: Intrathecal sufentanil appears to have a cardioprotective effect against myocardial ischemia-reperfusion injury in the experimental rabbit model (Tab. 1, Fig. 2, Ref. 19). Text in PDF www.elis.sk.

KEY WORDS: intrathecal sufentanil, preconditioning, myocardial ischemia-reperfusion, infarct size, hemodynamic changes.
\end{abstract}

\section{Introduction}

Ischemia triggers a series of cellular events, mild at the beginning, and increasing as the course of ischemia progresses. This condition is known as ischemic injury. Ischemia is terminated by reperfusion, which is necessary for cellular survival and normal cell function, but contrastingly, leads to cellular injury known as reperfusion injury (1). Preconditioning is an intrinsic response of the body that produces an adaptive resistance against more severe trauma through the production of sub-lethal metabolic stress (2). Ischemic preconditioning, remote ischemic preconditioning, and ischemic post-conditioning are the mechanisms aimed at re-

${ }^{1}$ Konya Public Hospitals Association, Health Sciences University, Konya Meram Education and Research Hospital, Konya, Turkey, ${ }^{2}$ Necmettin Erbakan University, Meram Faculty of Medicine, Department of Anesthesiology and Reanimation, Konya, Turkey, Necmettin Erbakan University, Meram Faculty of Medicine, Department of Pathology, Konya, Turkey, ${ }^{4}$ Bolu Izzet Baysal State Hospital, Cardiovascular Surgery Clinic, Bolu, Turkey, and ${ }^{5}$ Necmettin Erbakan University, Meram Faculty of Medicine, Department of Anesthesiology and Reanimation, Department of Algology, Konya, Turkey Experimental Study Institution: Necmettin Erbakan University Experimental Medical Practice and Research Center, Konya, Turkey

Address for correspondence: Y. Tire, Konya Public Hospitals Association, Health Sciences University, Konya Meram Education and Research Hospital, Konya, Turkey, PK: 42090 No: 97, Meram, Konya, Turkey. Phone: +5055367970 , Fax: +3323236723 ducing ischemia-reperfusion (IR) injury. Pharmacologic agents have cardioprotective effects through the activation of various cardiomyocyte receptors, especially adenosine, bradykinin, and opioid receptors, intracellular signal transduction pathways, and mitochondria (3).

Opioid receptor agonists increase myocardial tolerance during IR injury. Their infarct-reducing effect is observed both during prophylaxis and also during an acute treatment before reperfusion. Opioids have also been shown to be effective in the prevention of ischemia-induced arrhythmia (4). The role of sufentanil (selective mu-opioid receptor agonist) against IR injury has been investigated and the cardioprotective effect of intravenously-administered sufentanil in clinical and experimental models was shown (5-8).

Despite recent studies on sufentanil, no clinical and experimental studies associated with its central nervous system application have been reported to date. Therefore, in the present study, we aimed to investigate the cardioprotective effect and hemodynamic response of intrathecally (IT)-administered sufentanil on myocardial IR injury.

\section{Methods}

This study was conducted at the Experimental Medicine Research and Application Center after obtaining approval from the 
local Experimental Animals Ethics Committee (Decision date: 31.10.2011, No: 2011-109).

Thirty-two three-month-old New Zealand-type rabbits weighing between 1900 and $2360 \mathrm{~g}$ were used in the study. Before the study, the rabbits were subjected to a 12-hour cycle of light and darkness with no restriction on food and water.

\section{Surgical preparation}

The rabbits were weighed prior to the procedure and an anesthetic mixture of ketamine hydrochloride $(30 \mathrm{mg} / \mathrm{kg})$ and xylazine hydrochloride $(10 \mathrm{mg} / \mathrm{kg})$ was administered intramuscularly. Maintenance anesthesia was provided intramuscularly every 45 minutes and when necessary. The sedated rabbits were fixed on a wooden block with the surgical area shaved and cleaned with povidone iodine solution. An intravenous route was opened through the lateral vein of the ear using a 22-gauge cannula. A continuous infusion of $20 \mathrm{~mL} / \mathrm{kg} / \mathrm{h}$ Ringer's lactate solution was provided.

A three-lead electrode with metal clamps was placed on the chest wall. Monitoring of $\mathrm{D}_{\mathrm{II}}$ and $\mathrm{V}_{5}$ leads was initiated. The body temperature was monitored using a rectal temperature probe and maintained at $37-38^{\circ} \mathrm{C}$ using an external heating device. Following non-invasive monitoring, access to the trachea was performed through a superficial cut at the midline of the neck into the subcutaneous tissues. A 22-gauge cannula was placed in the right carotid artery lateral to the trachea and connected to the transducer, which was filled with heparinized fluid; invasive arterial blood pressure monitoring was then initiated. A tracheal cut was then made and a No. 3 endotracheal tube was inserted, followed by the formation of a neuromuscular non-depolarizing agent (rocuronium bromide) and connection to a ventilator (100\% oxygen, tidal volume: 10 $\mathrm{mL} / \mathrm{kg}$; respiratory rate: 20 to $30 / \mathrm{min}$ ).

The heart was accessed through a left thoracotomy via the fourth and fifth intercostal space. The pericardium was opened and the left coronary artery was reached immediately below the left atrial appendage. After preparation for surgery, the heart rate was left for 15 minutes to stabilize. This was followed by an injection of heparin (250 IU) via the ear vein. In the ischemic group, IR was provided by a clamp to the left anterior descending (LAD) artery. The presence of ischemia was confirmed by ST segment elevation on electrocardiography, and observation of cyanosis and hypokinetic areas on the LAD artery trace. A fall of the mean arterial pressure to below $50 \mathrm{mmHg}$ was considered as the presence of hypotension, and $5 \mathrm{mg}$ intravenous ephedrine was administered.

The rabbits were divided into the four groups: sham group ( $\mathrm{n}$ $=8)$, IR group $(\mathrm{n}=8)$, IT sufentanil group $(\mathrm{n}=8)$, and the IR + sufentanil group $(\mathrm{n}=8)$.

Sham $=$ Left thoracotomy was performed and the rabbits were monitored for $150 \mathrm{~min}$ without ischemia-reperfusion.

$\mathrm{IR}=$ Left thoracotomy was performed, then the LAD was subjected to $30 \mathrm{~min}$ of ischemia followed by $120 \mathrm{~min}$ of reperfusion.

Sufentanil $=$ After IT administration of $2.5 \mu \mathrm{g} / 0.5 \mathrm{~mL}$ sufentanil, left thoracotomy was performed and the rabbits were monitored for $150 \mathrm{~min}$ without ischemia-reperfusion.

$\mathrm{IR}+$ sufentanil $=$ After intrathecal administration of $2.5 \mu \mathrm{g} / 0.5$ $\mathrm{mL}$ sufentanil, a left thoracotomy was performed, then the LAD was subjected to $30 \mathrm{~min}$ of ischemia followed by $120 \mathrm{~min}$ of reperfusion.

Baseline hemodynamic parameters (mean arterial pressure and heart rate) were recorded 15 min after all surgical procedures were completed.

In the ischemia groups, measurements were made at the 10th and 30 th min of ischemia and at the 60th and 120th min of reperfusion; measurements were made at the 10th, 30th, 60th, and 120th $\min$ in the non-ischemic groups.

A 27-gauge needle was inserted from the L4 -5 space into the interspinous space at the level of the posterior superior iliac crest; $2.5 \mu \mathrm{g} / 0.5 \mathrm{~mL}$ of sufentanil $(5 \mu \mathrm{g} / \mathrm{mL})$ was then injected after obtaining caudal and plantar reflexes.

The LAD artery was occluded for a short period after reperfusion and $2 \% / \mathrm{mL}$ Evans Blue was administered intravenously through the ear vein. After staining body fluids blue by perfusion for a short period, all rabbits were sacrificed with $1 \mathrm{~mL}$ intravenous ketamine.

\section{Histopathologic analysis}

The heart was removed after the animals were sacrificed. The tissues were wrapped in a stretch film to prevent dying of the tissues and to facilitate better penetration of the stain into tissues. After storage for $30 \mathrm{~min}$ at $-55^{\circ} \mathrm{C}$, they were separated into five parts. Intubation at $37{ }^{\circ} \mathrm{C}$ for 20 min was performed using a buffer ( $\mathrm{pH} 7.4$ ) containing a $1 \%$ 2,3,5-triphenyl tetrazolium chloride (TTC) stain. The tissue parts were then put into $10 \%$ formaldehyde solution. Areas that maintained tissue viability were stained dark red with TTC. Necrotic areas, on the other hand, were observed as pale, yellowish brown. Parts of the heart were placed between two glass plates that were $2 \mathrm{~mm}$ apart, and pressed together using two clamps placed on the sides. Images of each of the two crosssections were taken. The borders of the necrotic regions (TTCnegative tissue) and risk areas (areas that contained no fluorescent particles under ultraviolet light) were marked on transparent acetate that was placed on the glass. The ratio of ischemic regions to risk areas was calculated. This ratio was used to compare the differences between the groups.

Tab. 1. Hemodynamic variables.

\begin{tabular}{cccccc}
\hline & $\begin{array}{c}\text { Sham } \\
(\mathrm{n}=8)\end{array}$ & $\begin{array}{c}\mathrm{I} / \mathrm{R} \\
(\mathrm{n}=8)\end{array}$ & $\begin{array}{c}\text { Sufentanil } \\
(\mathrm{n}=8)\end{array}$ & $\begin{array}{c}\mathrm{IR}+\text { Sufentanil } \\
(\mathrm{n}=8)\end{array}$ & $\mathrm{p}$ \\
\hline $\mathrm{HR}$ & & & & & \\
$\mathrm{T}_{1}$ & $161.0 \pm 30.5$ & $147.0 \pm 22.4$ & $192.0 \pm 20.0$ & $183.3 \pm 37.1$ & $0.030^{\mathrm{a}}$ \\
$\mathrm{T}_{2}$ & $172.5 \pm 37.8$ & $167.0 \pm 34.2$ & $197.8 \pm 20.3$ & $193.9 \pm 42.7$ & 0.304 \\
$\mathrm{~T}_{3}$ & $187.8 \pm 34.9$ & $199.5 \pm 30.3$ & $205.5 \pm 24.5$ & $210.0 \pm 35.1$ & 0.636 \\
$\mathrm{~T}_{4}$ & $186.6 \pm 37.0$ & $187.8 \pm 28.8$ & $228.1 \pm 26.3$ & $211.1 \pm 38.9$ & 0.080 \\
$\mathrm{~T}_{5}$ & $207.1 \pm 17.9$ & $176.0 \pm 33.6$ & $225.4 \pm 26.5$ & $227.1 \pm 32.1$ & $0.009^{\mathrm{b}}$ \\
\hline $\mathrm{MAP}$ & & & & & \\
$\mathrm{T}_{1}$ & $73.4 \pm 13.3$ & $74.3 \pm 18.9$ & $73.8 \pm 20.7$ & $67.5 \pm 11.3$ & 0.078 \\
$\mathrm{~T}_{2}$ & $61.8 \pm 8.9$ & $64.6 \pm 14.0$ & $60.5 \pm 8.9$ & $62.5 \pm 15.1$ & 0.504 \\
$\mathrm{~T}_{3}$ & $59.8 \pm 6.8$ & $63.4 \pm 6.9$ & $57.5 \pm 7.3$ & $56.6 \pm 8.5$ & 0.077 \\
$\mathrm{~T}_{4}$ & $67.4 \pm 13.6$ & $62.3 \pm 12.4$ & $55.3 \pm 8.1$ & $63.5 \pm 9.9$ & 0.294 \\
$\mathrm{~T}_{5}$ & $64.0 \pm 12.6$ & $69.8 \pm 11.4$ & $59.3 \pm 15.9$ & $64.6 \pm 5.5$ & 0.224 \\
\hline
\end{tabular}

$\mathrm{HR}=$ heart rate, $\mathrm{MAP}=$ mean arterial pressure, $\mathrm{T}_{1}=$ baseline, $\mathrm{T}_{2}=$ ischemia 10th $\min , \mathrm{T}_{3}=$ ischemia 30th $\mathrm{min}, \mathrm{T}_{4}=$ reperfusion 60th $\mathrm{min}, \mathrm{T}_{5}=$ reperfusion 120 th $\mathrm{min}$, $\mathrm{a}=\mathrm{I} / \mathrm{R}-$ Sufentanil $\mathrm{p}<0.05,{ }^{\mathrm{b}}=\mathrm{I} / \mathrm{R}-\mathrm{I} / \mathrm{R}+$ Sufentanil $\mathrm{p}<0.05$ 


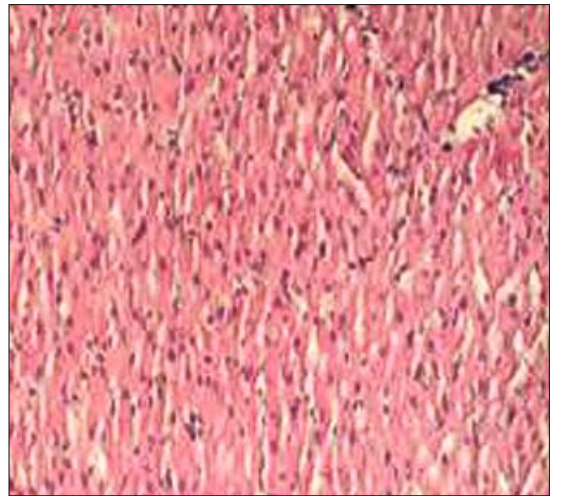

Sham

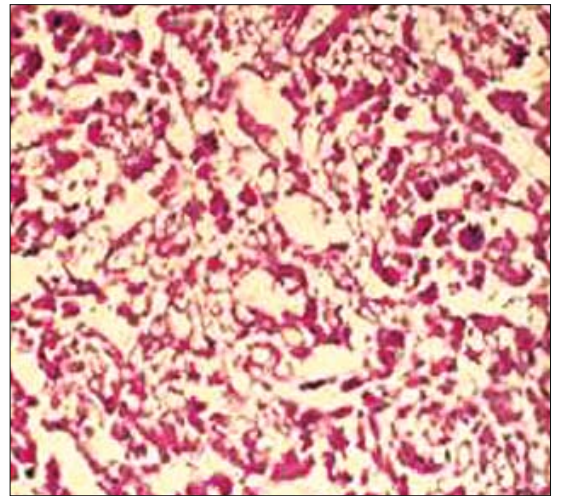

I/R

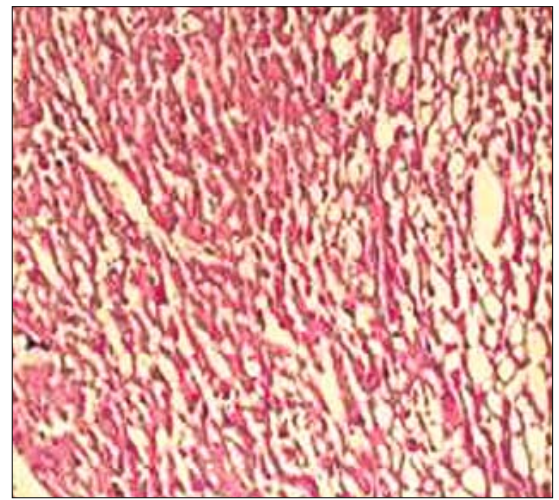

I/R + Sufentanil

Fig. 1. Myocardial Tissue Cell Morphology (MTC): sham, I/R (ischemia-reperfusion), and I/R + sufentanil (hematoxylin eosin). (MTC $\times 100)$.

\section{Statistical analysis}

Data were analyzed using the Mann-Whitney U test to evaluate variables between two groups; comparisons between more than two groups without normal distribution were made using the Bonferroni-corrected Kruskal-Wallis H test. $\mathrm{p}$ value of $<0.05$ was considered statistically significant.

\section{Results}

The four experimental subjects that were lost for various reasons were replaced by others and the study was terminated with a total of 32 rabbits. The weights of the experimental animals were similar (minimum $1750 \mathrm{~g}$, maximum $2450 \mathrm{~g}$ ) ( $\mathrm{p}>0.05$ ).

\section{Hemodynamic variables}

The mean arterial blood pressure was found to be similar between the groups for measurements performed at baseline, at the 10th and 30th min of ischemia, and at the 60th and 120th min of reperfusion $(\mathrm{p}>0.05)$.

There was a difference in the baseline heart rate between the IR and sufentanil groups; however, it was significant between the IR and IR + sufentanil groups in the 120th min values $(p<0.05)$. The measurements of ischemia at the 10th and 30th min and those of reperfusion at the 60th min were found to be similar between the groups $(\mathrm{p}>0.05)$ (Tab. 1).

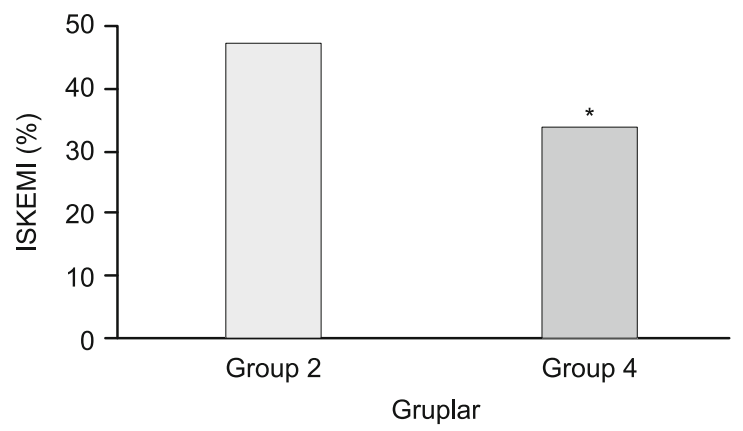

Fig. 2. Myocardial infarct size.

\section{Myocardial infarct size}

In the IR group, severe hydropic degeneration, vacuolization, and disorganization were observed in myocardial muscles in images obtained from the light microscopy evaluation of cell morphology with hematoxylin-eosin staining. In the IR + sufentanil group, a significant decrease in hydrops and vacuolization was observed (Fig. 1). The histopathologic examination demonstrated an infarct size of $47.5 \pm 7.0 \%($ minimum $=39.2$, maximum $=58.2)$ in the IR group and $34.2 \pm 4.7 \%$ (minimum $=28.3$, maximum $=$ 42.2) in the IR + sufentanil group. The infarct size was found to be statistically significantly smaller in the IR+sufentanil group (p $=0.002$ ) (Fig. 2).

\section{Discussion}

In our rabbit model of myocardial ischemia-reperfusion injury, IT sufentanil reduced myocardial infarct size. Hemodynamic parameters did not change significantly. This is the first study to demonstrate a decrease of myocardial IR injury by IT sufentanil.

Opioid receptor systems are known to be activated under stress. A crosstalk has been described in the heart involving the interaction and modulation of both opioid receptors and the other receptors. This often occurs directly or indirectly. Furthermore, several peptides such as: endorphins and encephalin are known to modify cellular functions in different cell types, independent of opioid receptors. Pharmacologic protection with opioid agents include pre- and post-conditioning, centrally-mediated opioidergic conditioning, and prolonged opioid receptor-mediated cardio protection. Pathologic processes such as : aging, comorbidities, and drugs, may also significantly alter cardiovascular responses to exogenous opioids (2).

Groban et al (9) administered IT morphine ( 0.3 or $3 \mu \mathrm{g} / \mathrm{kg}$ ) and intravenous morphine $(0.3 \mathrm{mg} / \mathrm{kg})$ to Wistar-type rats. For the first time, they demonstrated that IT morphine was as effective at protecting the heart as intravenous morphine. However, the mechanism of this cardioprotective effect has not been studied.

Subsequently, the role of opioid receptors in IT morphine preconditioning was investigated by Li et al (10) IT morphine 
preconditioning was similar to ischemic and intravenous morphine preconditioning. The IT morphine preconditioning effect was abolished by intrathecal administration of any of the opioid receptor antagonists (mu, delta, and kappa). Thus, the role of delta, kappa, and mu-opioid receptors in IT morphine preconditioning has been demonstrated.

In another study investigating the effect of opioid receptors, three consecutive infusions of $1 \mu \mathrm{g} / \mathrm{kg}$ IT morphine for $5 \mathrm{~min}$ were administered before ischemia. In addition, the effects of intrathecal and intravenous naloxone methiodide, a peripheral non-selective opioid receptor antagonist, were also evaluated. A comparison of the infarct size to the risk zone ratio with that of the control group $(48 \pm 9 \%)$ demonstrated that there was a significant difference between ischemic $(22 \pm 3 \%)$ and IT morphine (26 $\pm 5 \%$ ) preconditioning. The effect of morphine preconditioning $(45 \pm 4 \%)$ was reported to decrease with the administration of IT naloxone methiodide. However, IT morphine preconditioning $(28 \pm 9 \%)$ was not reversed by intravenous naloxone methiodide administration. The role of central opioid receptors in myocardial protection has been demonstrated in IT morphine preconditioning (11). Similarly, central opioid receptors have also been demonstrated to play a role during IT morphine postconditioning (12). Furthermore, IT morphine activates a neural pathway, in which spinal opioid receptors use non-opioid neurotransmitters for cardio protection (13).

The central endorphinergic system plays a role in intracerebroventricular morphine preconditioning signals. This cardioprotective effect is mainly due to an increase in levels of central beta endorphin in the serum, pituitary gland, ventrolateral periaqueductal gray and rostral ventrolateral medulla (14).

Intracerebroventricular morphine administration results in an increase of the expression of calcitonin in the hippocampus, which causes calcitonin gene-related peptide release, which then plays a role in remote preconditioning. In addition to the three opioid receptors, this route is suggested as the mechanism associated with the cardioprotective effect of intracerebroventricular morphine (15).

Both central and peripheral adenosine receptors may participate in IT morphine preconditioning signals. Central receptors play an important role at the beginning of the procedure, and peripheral receptors have a role in the continuation of this effect (16). The recent study also emphasized that spinal mu-opioid receptors and the activation of nitric oxide synthase (NOS) signaling were involved in the cardioprotective effects of IT morphine (17).

In the experimental rat model by Adam et al (18), the analgesic effects of intravenous and intrathecal sufentanil were investigated, and ED50s were found to be similar in both routes of administration. This is explained by the high lipid solubility of sufentanil.

In the recently conducted study, it was shown that a totall $\mu \mathrm{g} /$ $\mathrm{kg}$ intravenous dose of sufentanil had cardioprotective effects on rabbits (8). In our study, the IT sufentanil dose was determined as $2.5 \mu \mathrm{g}$. This dose used in our study is close to the intravenous dose used previously (approximately $1 \mu \mathrm{g} / \mathrm{kg}$ ). The IT sufentanil dose used in our study was observed to reduce the area of infarct on rabbit myocardium subjected to IR.
A low mean arterial pressure and a high heart rate may increase infarct size. This property is particularly important for experimental models with a high collateral blood flow. However, collateral circulation is limited $(2 \%)$ in rabbits and a decreased arterial pressure is unimportant in myocardial infarct size. Therefore, hemodynamic changes may be negligible in rabbit models (19). The mean arterial pressure showed a similar course between the groups. In the IR group, the heart rate was lower at baseline and at $120 \mathrm{~min}$ of reperfusion than in the sufentanil and $\mathrm{I} / \mathrm{R}+$ sufentanil groups, respectively, but this is clinically unimportant In conclusion, IT sufentanil appears to have a cardioprotective effect in the experimental rabbit models of myocardial IR injury. However, there is a need for further clinical and experimental studies, in which various routes of administration and doses of sufentanil and the underlying mechanisms are investigated.

\section{References}

1. Kato R, Foëx P. Myocardial protection by anesthetic agents against ischemia-reperfusion injury: an update for anesthesiologists. Can J Anaesth 2002; 49: 777-791.

2. Headrick JP, See Hoe LE, Du Toit EF, Peart JN. Opioid receptors and cardioprotection-'opioidergic conditioning' of the heart. Br J Pharmacol 2015; 172: 2026-2050.

3. Sivaraman V, Yellon DM. Pharmacologic therapy that simulates conditioning for cardiac ischemic/reperfusion injury. J Cardiovasc Pharmacol Ther 2014; 19: 83-96.

4. Maslov LN, Khaliulin I, Oeltgen PR, Naryzhnaya NV, Pei JM, Brown SA et al. Prospects for creation of cardioprotective and antiarrhythmic drugs based on opioid receptor agonists. Med Res Rev2016; 36: 871-923.

5. Wu QL, Shen T, Ma H, Wang JK. Sufentanil postconditioning protects the myocardium from ischemia-reperfusion via PI3K/Akt-GSK-3 $\beta$ pathway. J Surg Res2012; 178: 563-570.

6. Wu Y, Gu EW, Zhu Y, Zhang L, Liu XQ, Fang WP. Sufentanil limits the myocardial infarct size by preservation of the phosphorylated connexin 43. Int Immunopharmacol 2012; 13: 341-346.

7. Zuo Y, Cheng X, Gu E, Liu X, Zhang L, Cao Y. Effect of aortic root infusion of sufentanil on ischemia-reperfusion injury in patients undergoing mitral valve replacement. J Cardiothorac Vasc Anesth 2014; 28 : 1474-1478.

8. Wang XH, Zeng JF, Lin C, Chen SB. Effects of morphine and sufentanil preconditioning against myocardial ischemic-reperfusion injury in rabbits. Int J Clin Exp Med 2015; 8: 15692-15699.

9. Groban L, Vernon JC, Butterworth J. Intrathecal morphine reduces infarct size in a rat model of ischemia-reperfusion injury. Anesth Analg 2004; 98: 903-909.

10. Li R, Wong GT, Wong TM, Zhang Y, Xia Z, Irwin MG. Intrathecal morphine preconditioning induces cardioprotection via activation of delta, kappa, and mu opioid receptors in rats. Anesth Analg 2009; 108: 23-29.

11. Wong GT, Ling Ling J, Irwin MG. Activation of central opioid receptors induces cardioprotection against ischemia-reperfusion injury. Anesth Analg 2010; 111: 24-28. 
240-244

12. Ling Ling J, Wong GT, Yao L, Xia Z, Irwin MG. Remote pharmacological post-conditioning by intrathecal morphine: cardiac protection from spinal opioid receptor activation. Acta Anaesthesiol Scand 2010; 54: 1097-1104.

13. Wong GT, Yao L, Xia Z, Irwin MG. Intrathecal morphine remotely preconditions the heart via a neural pathway. J Cardiovasc Pharmacol 2012; 60: 172-178.

14. Cheng X, Zhang YE, Lu X, Lu Y, Chen Z. The involvement of central beta-endorphin in the cardioprotective effects of remote preconditioning mediated by the intracerebroventricular administration of morphine. Ir J Med Sci 2016; 185: 423-431.

15. Zhang Y, Irwin MG, Lu Y, Mei B, Zuo YM, Chen ZW et al. Intracerebroventricular administration of morphine confers remote cardioprotection - role of opioid receptors and calmodulin. Eur J Pharmacol 2011; 656: 74-80.
16. Yao L, Wong GT, Xia Z, Irwin MG. Interaction between spinal opioid and adenosine receptors in remote cardiac preconditioning: effect of intrathecal morphine. J Cardiothorac Vasc Anesth 2011; 25: 444-448.

17. Jiang L, Hu J, He S, Zhang L, Zhang Y. Spinal neuronal NOS signaling contributes to morphine cardioprotection in ischemia reperfusion injury in rats. J Pharmacol Exp Ther 2016; 358: 450-456.

18. Adam F, Le Bars D, Chauvin M, Guirimand F. Effects of intravenous and intrathecal sufentanil on a $\mathrm{C}$-fibre reflex elicited by a wide range of stimulus intensities in the rat. Eur J Pharmacol 2001; 411: 93-106.

19. Ross S, Foëx P. Protective effects of anaesthetics in reversible and irreversible ischaemia-reperfusion injury. Br J Anaesth 1999; 82: 622-632.

Received January 8, 2018. Accepted January 29, 2018. 